\title{
Understanding Chemical Stability Issues between Different Solid Electrolytes in All-Solid-State Batteries
}

\author{
Nathalie Riphaus, $\oplus^{1,2, z}$ Barbara Stiaszny, ${ }^{2}$ Hans Beyer, ${ }^{1}$ Sylvio Indris, $\oplus^{3,4}$ \\ Hubert A. Gasteiger, ${ }^{1, *}$ and Stefan J. Sedlmaier ${ }^{2}{ }^{2}$

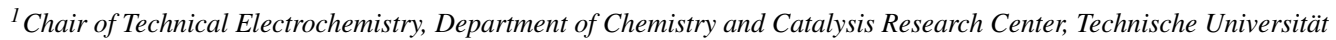 \\ München, 85748 Garching, Germany \\ ${ }^{2}$ BMW Group, 80809 Munich, Germany \\ ${ }^{3}$ Institute for Applied Materials - Energy Storage Systems, Karlsruhe Institute of Technology, 76344 \\ Eggenstein-Leopoldshafen, Germany \\ ${ }^{4}$ Helmholtz Institute Ulm, 89081 Ulm, Germany
}

\begin{abstract}
Sulfide-based solid electrolytes (SE) are quite attractive for application in all-solid-state batteries (ASSB) due to their high ionic conductivities and low grain boundary resistance. However, limited chemical and electrochemical stability demands for protection on both cathode and anode side. One promising concept to prevent unwanted reactions and simultaneously improve interfacial contacting at the anode side consists in applying a thin polymer film as interlayer between Li metal and the SE. In the present study, we investigated the combination of polyethylene oxide (PEO) based polymer films with the sulfide-based $\mathrm{SE} \mathrm{Li}_{10} \mathrm{SnP}_{2} \mathrm{~S}_{12}$ (LSPS). We analyzed their compatibility using both electrochemical and chemical techniques. A steady increase in the cell resistance during calendar aging indicated decomposition reactions at the interfaces. By means of X-ray photoelectron spectroscopy and further analytical methods, the formation of polysulfides, $\mathrm{P}-[\mathrm{S}]_{\mathrm{n}}-\mathrm{P}$ like bridged $\mathrm{PS}_{4}{ }^{3-}$ units and sulfite, $\mathrm{SO}_{3}{ }^{2-}$, was demonstrated. We critically discuss potential reasons and propose a plausible mechanism for the degradation of LSPS with PEO. The main objective of this paper is to highlight the importance of understanding interfaces in ASSBs not only from an electrochemical perspective, but also from a chemical point of view.

(C) The Author(s) 2019. Published by ECS. This is an open access article distributed under the terms of the Creative Commons Attribution 4.0 License (CC BY, http://creativecommons.org/licenses/by/4.0/), which permits unrestricted reuse of the work in any medium, provided the original work is properly cited. [DOI: 10.1149/2.0351906jes]

(cc) BY
\end{abstract}

Manuscript submitted February 11, 2019; revised manuscript received March 8, 2019. Published March 26, 2019. This was Paper 488 presented at the Seattle, Washington Meeting of the Society, May 13-17, 2018.

It is often discussed that it might be difficult with today's Li-ion cell technologies to meet future long term targets for application in battery electric vehicles (BEV). ${ }^{1-3}$ In particular, the increasing demand for extended driving ranges, which comes along with higher energy density, conflicts with the limited energy density of conventional Li-ion batteries. ${ }^{1}$ While gravimetric energy densities exceeding $300 \mathrm{Wh} \cdot \mathrm{kg}^{-1}$ are targeted at cell level, only up to $170 \mathrm{Wh} \cdot \mathrm{kg}^{-1}$ were reached in current EVs. ${ }^{4}$ In addition, high power density is desired due to fastcharging requirements. ${ }^{1}$ Consequently, battery research was extended to novel cell technologies. Solid electrolytes (SE) have attracted growing interest as they have the potential to enable the use of metallic $\mathrm{Li}$ as anode material. They feature several advantages over liquid electrolytes, such as a rigid and non-leaking structure, non-flammability as well as a larger temperature operation range. ${ }^{1,5}$ All-solid-state batteries (ASSB) thus have great potential to simultaneously enhance safety, lifetime and energy density compared to established Li-ion cell technologies. ${ }^{2}$

Initially, poor ionic conductivity at ambient temperature has been regarded as the major drawback of SEs, but recent reports prove that this challenge has been met with sulfide-based materials like $\mathrm{Li}_{10} \mathrm{GeP}_{2} \mathrm{~S}_{12}$ (LGPS) or $\mathrm{Li}_{2} \mathrm{~S} \cdot \mathrm{P}_{2} \mathrm{~S}_{5}$. They provide conductivities as high as $25 \mathrm{mS} \cdot \mathrm{cm}^{-1}$, exceeding that of current liquid electrolytes. ${ }^{6-9}$ Moreover, their softness allows for good contacting, thus providing lower grain-boundary and interfacial resistance compared to oxidebased SEs. High total cell resistance evolving from rigid solid-solid interfaces indeed is a major issue. ${ }^{5,10}$ In a pure solid system, volume changes of the active materials during cycling lead to a loss of interfacial contact and thus complicate realization of a bulk ASSB..$^{11,12}$ Another problem especially for sulfide-based SEs is their chemical instability not only in contact with air and moisture, but also with Li metal and the cathode materials. ${ }^{1,2,10,13}$ Furthermore, recent studies revealed that their electrochemical stability has generally been overestimated so far. ${ }^{14-16}$ According to Zhu et al., the rather slow decomposition kinetics at the SE/electrode interface, which only gradually lead to high overpotentials, are responsible for a seemingly large stability

\footnotetext{
*Electrochemical Society Fellow.
}

${ }^{\mathrm{z}}$ E-mail: nathalie.riphaus@tum.de window in most electrochemical materials stability screening tests. ${ }^{16}$ As a matter of fact, the rather poor oxidative/reductive stability of most SEs requires protection on both cathode and anode side. ${ }^{1}$

While coating of the active material is a common strategy to prevent unwanted reactions at the cathode interface, ${ }^{17}$ different approaches aim for overcoming decomposition issues at the interface with the Li metal anode. Numerous examples of sputtering thin interlayers onto the SE and Li metal, respectively, have been reported. ${ }^{18-21} \mathrm{Li}$-ion conductors such as LiPON, ${ }^{18}$ metals like indium ${ }^{22}$ or gold $^{21}$ as well as metalloids such as silicon ${ }^{19}$ have been proven to effectively prevent decomposition reactions between SEs and metallic Li. However, most sputtering techniques are expensive and thus less attractive for largescale applications. Moreover, limited ionic conductivity as well as degradation of the interlayers still questions their suitability. ${ }^{23}$

An alternative concept, which has been studied in liquid electrolyte based $\mathrm{LIBs}^{24,25}$ and in Li-air batteries using Li metal anodes, ${ }^{26}$ consists in application of a thin polymer film as interlayer. Polyethylene oxide (PEO) based solid polymer electrolytes (SPE) are well established in polymer-based ASSBs, and many successful examples have been reported in the literature. ${ }^{27-29}$ In contrast to inorganic SEs, SPEs provide a certain flexibility, ensuring good contacting at the interfaces. ${ }^{3,30}$

In a different study, PEO-based membranes were applied between electrodes and $\mathrm{Li}_{1+\mathrm{x}} \mathrm{Al}_{\mathrm{x}} \mathrm{Ti}_{2-\mathrm{x}}\left(\mathrm{PO}_{4}\right)_{3}(\mathrm{LATP}),{ }^{31}$ an oxide-based $\mathrm{SE}$ that is known to rapidly decompose in contact with metallic Li. ${ }^{10}$ Thereby, degradation reactions could be prevented, resulting in improved interfacial contacting and decreased interfacial resistance. Although it has recently been demonstrated that also PEO is thermodynamically not stable in contact with $\mathrm{Li}$ metal, the formed passivation layer allows for sufficient cycling behavior. ${ }^{3,30}$ Similarly, Zhou et al. reported a beneficial effect of the SPE | oxide-based SE | SPE sandwich architecture on cycling behavior and dendrite stability in lithium and sodium ASSB test cells. ${ }^{32,33}$ The same setup has been examined with regard to its ability to mitigate the risk of SE breakage as well as contact loss between SE and electrodes, ${ }^{34}$ which is a major issue during cycling due to volume expansions. ${ }^{11}$

Inspired by this promising concept, we investigated the combination of polymer interlayers with sulfide-based SEs, as they usually feature higher ionic conductivities than oxides. ${ }^{1,10}$ As a model electrolyte, 
we selected $\mathrm{Li}_{10} \mathrm{SnP}_{2} \mathrm{~S}_{12}$ (LSPS), the thiostannate analogue of LGPS that features a comparable conductivity of $2-4 \mathrm{mS} \cdot \mathrm{cm}^{-1}, 7,35$ while its cost is significantly lower due to the replacement of germanium with tin, making it more attractive for large-scale applications. ${ }^{7}$ The compatibility of LSPS with PEO has already been tested in a different context. Blanga et al. reported on a composite electrolyte showing improved cycling behavior and safety in Li/S batteries. ${ }^{36}$ They stated that prolonged annealing of a LSPS-PEO film with the salt LiI at $90^{\circ} \mathrm{C}$ results in the formation of a novel $\mathrm{Li}_{10+\mathrm{x}} \mathrm{I}_{\mathrm{x}} \mathrm{SnP}_{2} \mathrm{~S}_{12} / \mathrm{P}(\mathrm{EO})_{3} / \mathrm{LiI}$ electrolyte. X-ray photoelectron spectroscopy (XPS) and X-ray diffraction (XRD) were used to characterize the composite. The study though did not include post-mortem analysis, so no conclusions can be drawn with respect to the chemical stability between LSPS and PEO. To the best of our knowledge, this has also not yet been reported elsewhere. In the present study, we analyzed the compatibility of LSPS with PEO-based membranes by examining the interfacial resistance using electrochemical impedance spectroscopy (EIS), by characterizing the surface composition using XPS, as well as by applying further analytical methods. We found clear experimental evidence for the chemical reactivity of LSPS in contact with PEO and we critically discuss potential reasons and propose a plausible degradation mechanism.

\section{Experimental}

Materials.-All materials were handled within an argon filled glove box $\left(\mathrm{O}_{2}, \mathrm{H}_{2} \mathrm{O}<1\right.$ ppm; GS Glovebox Systemtechnik GmbH). $\mathrm{Li}_{10} \mathrm{SnP}_{2} \mathrm{~S}_{12}$ (>95\%, LSPS) was purchased from NEI Corporation and used without further purification. Polyethylene oxide (PEO, $\mathrm{M}_{\mathrm{w}} 10^{6} \mathrm{~g} \cdot \mathrm{mol}^{-1}$ ), polyethylene glycol dimethyl ether (PEGDME, $\mathrm{M}_{\mathrm{w}} 2000 \mathrm{~g} \cdot \mathrm{mol}^{-1}$ ) and bis(trifluoromethane)sulfonimide lithium salt $(99.95 \%$, LiTFSI) were purchased from Sigma Aldrich Corp. and dried in a vacuum oven (Büchi B-585 Drying) at $120^{\circ} \mathrm{C}$. SE pellets (ca. $0.5 \mathrm{~mm}$ of thickness) were obtained by compacting $100 \mathrm{mg}$ of LSPS powder within a $12 \mathrm{~mm}$ diameter stainless steel pellet die at 5 tons ( $\equiv 430 \mathrm{MPa}$ ) for $20 \mathrm{~min}$ inside the glove box. For preparation of PEO $_{15}$ LiTFSI membranes of a thickness of 30-50 $\mu \mathrm{m}, 1.25 \mathrm{~g}$ of PEO and $0.50 \mathrm{~g}$ of LiTFSI were homogenized using mortar and pestle and annealed for $72 \mathrm{~h}$ at $100^{\circ} \mathrm{C}$ under argon atmosphere. The material was hot-pressed between siliconized Mylar foils under argon atmosphere in a P $200 \mathrm{PM}$ press (Collin) at $100^{\circ} \mathrm{C}$ and $0.5 \mathrm{kN} \cdot \mathrm{cm}^{-2}$ for $15 \mathrm{~min}$. The same procedure was used for preparation of pure PEO and PEGDME membranes.

Cell assembly._Electrochemical measurements were conducted in air-tight two electrode TSC battery cells (rhd instruments). Cells were stacked in the following order: Li metal electrode (AlfaAesar, $\varnothing=10 \mathrm{~mm}, 750 \mu \mathrm{m}$ thickness $),$ PEO $_{15}$ LiTFSI membrane $(\varnothing=$ $12 \mathrm{~mm})$, LSPS pellet $(\varnothing=12 \mathrm{~mm})$, PEO $_{15}$ LiTFSI membrane $(\varnothing=$ $12 \mathrm{~mm})$, Li metal electrode $(\varnothing=10 \mathrm{~mm})$. Sufficient contacting was ensured by applying a constant pressure of 5 bar. Calendar aging tests of polymer membranes covered with LSPS powder were performed in air-tight ECC-std. cells (EL-cell GmbH). Stainless steel spacers of $0.5 \mathrm{~mm}$ and a hard spring $(32.6 \mathrm{Nm})$ served for sufficient contacting. Individual cells for storage experiments were welded into pouch bags (Showa Denko) under argon atmosphere in order to reliably assure the absence of air intrusion even over extended times. For investigations of the interfaces after cell testing, cells were disassembled and the individual layers were separated carefully using a tweezer.

Electrochemical impedance spectroscopy (EIS).-_EIS was probed in TSC battery cells (rhd instruments) with an Autolab M101 impedance analyzer (Metrohm) in a frequency range between $1 \mathrm{MHz}$ and $10 \mathrm{mHz}$ using an amplitude of $20 \mathrm{mV}$ in the temperature range from $20-60^{\circ} \mathrm{C}$. For calendar aging tests, the cells were kept at a defined temperature and EIS was measured every $12 \mathrm{~h}$ for 7-21 days. EIS spectra were evaluated using electrical equivalent circuits and the RelaxIS software package (rhd instruments).
X-ray photoelectron spectroscopy (XPS).—Samples were mounted floating on a stainless steel sample holder $(\varnothing=15 \mathrm{~mm})$ using adhesive copper tape inside the glove box. The sample holder was then transferred from the glove box into the load lock of the XPS system without air exposure using a transfer vessel (Kratos). XPS spectra were recorded with an Axis Supra system (Kratos) using monochromatic $\mathrm{Al} \mathrm{K}$ radiation $(\mathrm{h} v=1486.6 \mathrm{eV})$ in hybrid lens mode with the instrument's charge neutralizer turned on. Sputtering was performed using an argon ion cluster gun at an acceleration voltage of $10 \mathrm{kV}$ and an argon ion current of $1 \mu \mathrm{A}$. The obtained spectra were processed and fitted using the ESCApe software (Kratos, version 1.1). Binding energies were corrected based on the $\mathrm{C}-\mathrm{C} / \mathrm{C}-\mathrm{H}$ peak of adventitious carbon at $284.8 \mathrm{eV}$ in the $\mathrm{C} 1 \mathrm{~s}$ spectrum. A mixture of $30 \%$ Laurentzian and $70 \%$ Gaussian functions was used for the least-squares curves fitting procedure utilizing a Shirley background subtraction. For fitting of doublets, peak ratio and peak separation were fixed.

Fourier transform infrared spectroscopy (FTIR).- -Samples were investigated by FTIR inside the glove box. Spectra were recorded from $4000-380 \mathrm{~cm}^{-1}$ at a MIRacle Germanium ATR (Pike Technologies) incorporated in the spectrometer Spectrum Two (Perkin Elmer).

$\boldsymbol{U V}$-Vis spectroscopy.-Measurements were carried out at room temperature with a Lambda 35 UV-VIS Spectrometer (PerkinElmer). UV-Vis spectra were recorded in a wavelength range of 700-200 nm, at a scan rate of $60 \mathrm{~nm} / \mathrm{min}$, an interval of $1 \mathrm{~nm}$ and a slit width of $2 \mathrm{~nm}$, using the program UV Winlab (PerkinElmer). Sample preparation took place in the glove box. The samples were dissolved in dimethylacetamide (anhydrous, 99.8\%) or diglyme (anhydrous, 99.5\%, both Sigma Aldrich Corp.) and filled into an air-tight quartz cuvette with a thickness of $1 \mathrm{~mm}$.

Solid-state NMR spectroscopy.-Samples were filled into $2.5 \mathrm{~mm}$ $\mathrm{ZrO}_{2}$ rotors in an argon-filled glove box. ${ }^{31} \mathrm{P}$ and ${ }^{119} \mathrm{Sn}$ magic-angle spinning (MAS) NMR experiments were carried out with a Bruker Avance $500 \mathrm{MHz}$ spectrometer equipped with a $2.5 \mathrm{~mm}$ MAS NMR double-resonance probe at a spinning speed of $20 \mathrm{kHz}$. The magnetic field strength was $11.7 \mathrm{~T}$, corresponding to Larmor frequencies of 202.4 MHz $\left({ }^{31} \mathrm{P}\right)$ and 186.4 MHz $\left({ }^{119} \mathrm{Sn}\right)$. A rotor-synchronized Hahnecho pulse sequence was used for data acquisition with a $\pi / 2$ time of $2 \mu \mathrm{s}$ and recycle delays of $60 \mathrm{~s}$.

\section{Results and Discussion}

Stability of the LSPS | PEO ${ }_{15}$ LiTFSI interface.-In order to assess the compatibility of PEO $_{15}$ LiTFSI membranes with LSPS, we first investigated their electrochemical properties in symmetrical Li | PEO $_{15}$ LiTFSI | LSPS | PEO $_{15}$ LiTFSI | Li cells by means of EIS at different temperatures. In general, several contributions to the overall cell resistance are expected, namely from: (i) bulk and (ii) grainboundary resistance of LSPS; (iii) bulk resistance of $\mathrm{PEO}_{15}$ LiTFSI; (iv) interfacial resistance between Li metal and $\mathrm{PEO}_{15}$ LiTFSI; (v) interfacial resistance between LSPS and PEO $_{15}$ LiTFSI; and, (vi) semiinfinite diffusion in the SE sandwich layer. ${ }^{37,38}$

Representative impedance spectra for the first heating and cooling cycle (ca. $3 \mathrm{~h}$ holding time at each temperature) are shown in Figure 1. The initial high resistance of nearly $29 \mathrm{k} \Omega$ at $20^{\circ} \mathrm{C}$ is largely dominated by the contributions from the resistances (iii) - (v). The main reason for this is the poor ionic conductivity and flexibility of PEO at ambient temperature, which has been shown in various contexts before. ${ }^{39,40}$ To ensure sufficient contacting between PEO and Li metal, an initial conditioning step at elevated temperature is essential. ${ }^{30}$ This can be linked to the phase transition of PEO from crystalline to amorphous state, which is accompanied by a decrease in viscosity and thus allows better adhesion at the interfaces. ${ }^{3,41}$

As expected, EIS spectra recorded during the cool-down cycle showed remarkably lower overall cell impedances than the spectra at the same temperature during the heating cycle (e.g 15 vs. $29 \mathrm{k} \Omega$ at $20^{\circ} \mathrm{C}$ ), indicating that the interfacial resistances decreased. The 

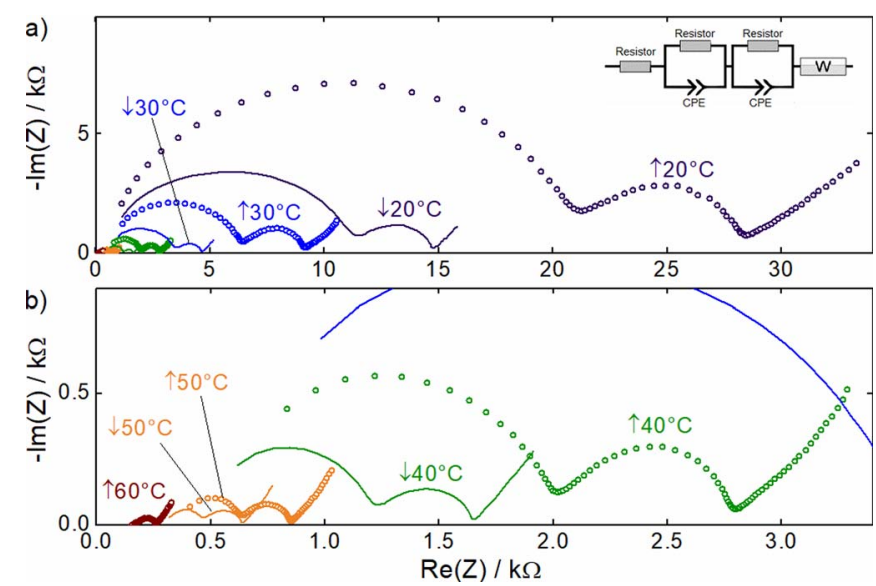

Figure 1. Nyquist diagram of the impedance of a Li $\mid$ PEO $_{15}$ LiTFSI $\mid$ LSPS $\mid$ PEO $_{15}$ LiTFSI $\mid \mathrm{Li}$ cell during the first heating (circles) and the subsequent cooling (lines) cycle from $20-60^{\circ} \mathrm{C}(1 \mathrm{MHz}$ to $10 \mathrm{mHz}$ with $20 \mathrm{mV}$ amplitude; ca. $3 \mathrm{~h}$ holding time at each temperature). The electric equivalent circuit used for fitting is shown in the top right.

electric equivalent circuit used to fit the experimental impedance results is shown in the top right of Figure 1. As the bulk and grainboundary resistances of LSPS (i.e. (i) and (ii) listed above) are very small in the here measured temperature range, their contributions are expected to appear beyond the maximum applied frequency of $1 \mathrm{MHz} .{ }^{42}$ Hence, they cannot be resolved and are included in the serial resistor (s. left-most resistor in the inset of Figure 1), along with electrical resistances of the cables and the cell body. Transport through the $\mathrm{PEO}_{15}$ LiTFSI films and across the $\mathrm{PEO}_{15}$ LiTFSI $\mid \mathrm{Li}$ and the PEO $_{15}$ LiTFSI | LSPS interfaces (contributions (iii) - (v)) appear as semicircles in the Nyquist plot and are thus modeled by a parallel circuit of a resistor and a capacitor. To account for the non-ideal capacitive behavior of solid-solid interfaces, indicated by a depression of the semicircles in Figure 1, constant phase elements (CPE) were used instead of ideal capacitors, in accordance with previous reports. ${ }^{15,43,44}$ The semi-infinite diffusion in the SE layer (vi), which appears as a $45^{\circ}$ line in the low frequency region, is fitted by a Warburg diffusion element. ${ }^{37,44}$

Fitting of the semicircle in the high frequency (HF) region revealed capacitances in the $\mathrm{nF}$ range, corresponding to a time constant on the order of milliseconds for the HF process. The middle-frequency (MF) semicircle, in contrast, showed capacitances in the $\mu \mathrm{F}$ range, corresponding to a time constant on the order of microseconds. For a clear assignment of the two processes to the contributions (iii) - (v), comparative measurements were performed with $\mathrm{Li}\left|\mathrm{PEO}_{15} \mathrm{LiTFSI}\right| \mathrm{Li}$ and SS | PEO $_{15}$ LiTFSI | LSPS | PEO $_{15}$ LiTFSI | SS cells, where SS represents the stainless steel current collector. An exemplary Nyquist and Bode plot of the impedance of the three different cell configurations at $20^{\circ} \mathrm{C}$ is shown in Figure 2. The MF process (ascribed to the right semicircle in Figure 2a) can only be found in those cells comprising $\mathrm{Li}$ metal, and thus it can be assigned to the $\mathrm{Li} \mid \mathrm{PEO}_{15} \mathrm{LiTFSI}$ interface (iv). The capacitance on the order of $\mu \mathrm{F}$ is in good agreement with previously reported values. ${ }^{38,45}$ On the other hand, the HF process (ascribed to the left semicircle in Figure $2 b$ ) occurs in all cells, indicating that it is linked to Li-ion transport in the polymer layer (iii) as well

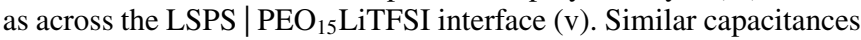
have been reported for RCPE elements describing Li-ion transport across the SE layer. ${ }^{42,44}$

In order to evaluate the calendar aging of these cells, time-resolved EIS was performed at $40^{\circ} \mathrm{C}$ (after prior heating to $60^{\circ} \mathrm{C}$ ). Impedance spectra recorded over the course of one week are shown in Figure 3 , demonstrating a steady rise in cell impedance with time. Fitting was performed using the same equivalent circuit model as for the temperature-dependent EIS spectra (Figure 1). The resistance of the HF process was increasing slightly, while the capacitance remained
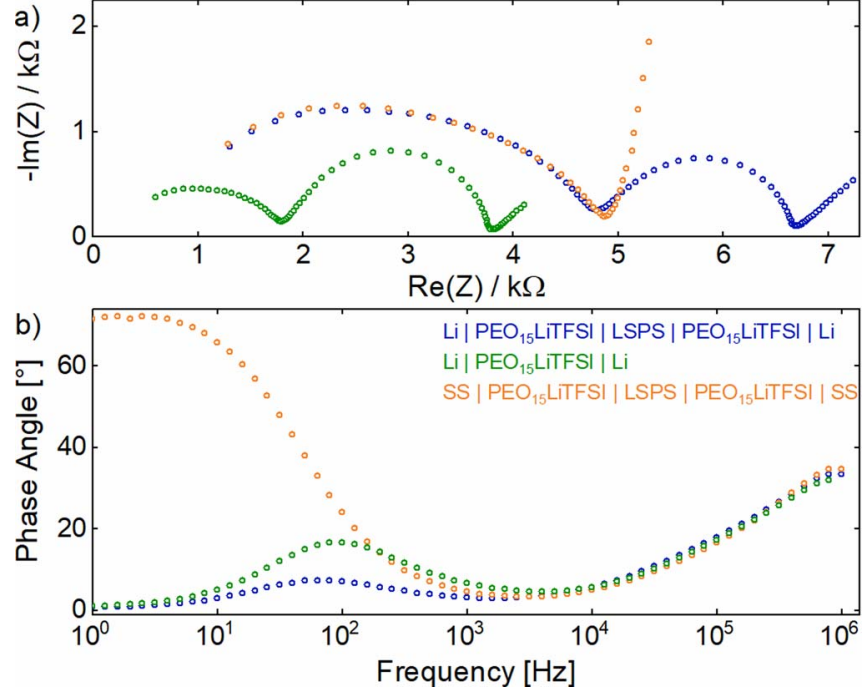

Figure 2. a) Nyquist and b) Bode diagram of the impedance of three different cell setups at $20^{\circ} \mathrm{C}$ prior to any heating cycle ( $1 \mathrm{MHz}$ to $1 \mathrm{~Hz}$ with $20 \mathrm{mV}$ amplitude): Li | PEO $_{15}$ LiTFSI | LSPS | PEO ${ }_{15}$ LiTFSI | Li (blue), Li | PEO ${ }_{15}$ LiTFSI | Li (green) and SS | PEO 15 LiTFSI | LSPS | PEO ${ }_{15}$ LiTFSI | SS (orange).

in the $\mathrm{nF}$ range. This might indicate an ongoing degradation process at the LSPS $\mid$ PEO $_{15}$ LiTFSI interface. In contrast, the MF process showed a strong increase in resistance with a simultaneous decrease in capacitance. This trend could arise from either contact losses or decomposition to result in electrochemically inactive species at the $\mathrm{Li} \mid \mathrm{PEO}_{15}$ LiTFSI interface. Similar conclusions were reached in previous studies. ${ }^{30,38,45}$ However, a clear assignment of the impedance rise to changes in the cell is difficult as the various contributions to the cell impedance partially overlap in the EIS spectra. For a more accurate analysis of the compatibility of the two electrolytes while excluding interfering influences from Li metal, stainless steel (SS) electrodes were used for subsequent testing.

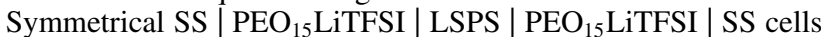
were built and characterized by EIS over time, likewise revealing a continuously rising cell impedance (Figure 4). Fitting required adoption of the equivalent circuit, as the resistance at the $\mathrm{Li} \mid \mathrm{PEO}_{15} \mathrm{LiTFSI}$ interface (process (iv)) is eliminated due to the absence of lithium. Instead, an additional constant phase element CPE3 was introduced to represent the SS $\mid \mathrm{PEO}_{15} \mathrm{LiTFSI}$ interface (Figure 4, top left). The values for $\mathrm{R}$ and $\mathrm{CPE}$ of the $\mathrm{HF}$ semicircle increased linearly. As for the cells with Li metal electrodes, the time constant was determined to in the microsecond range and can thus be assigned to the LSPS | PEO $_{15}$ LiTFSI interface. This growing resistance at the LSPS | PEO $_{15}$ LiTFSI interface clearly indicates chemical stability issues between LSPS and PEO $_{15}$ LiTFSI, further supported by the intense

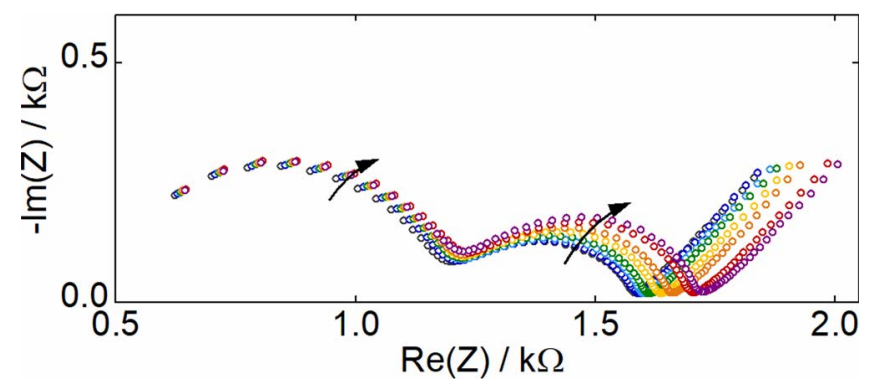

Figure 3. Nyquist diagram of the impedance of a Li $\mid$ PEO $_{15}$ LiTFSI $\mid$ LSPS $\left|\mathrm{PEO}_{15} \mathrm{LiTFSI}\right| \mathrm{Li}$ cell stored at $40^{\circ} \mathrm{C}$ after prior heating to $60^{\circ} \mathrm{C}(1 \mathrm{MHz}$ to $10 \mathrm{mHz}$ with $20 \mathrm{mV}$ amplitude). The arrows indicate the development over time, taken at 1-day intervals (blue: initial impedance, pink: after 7 days). 


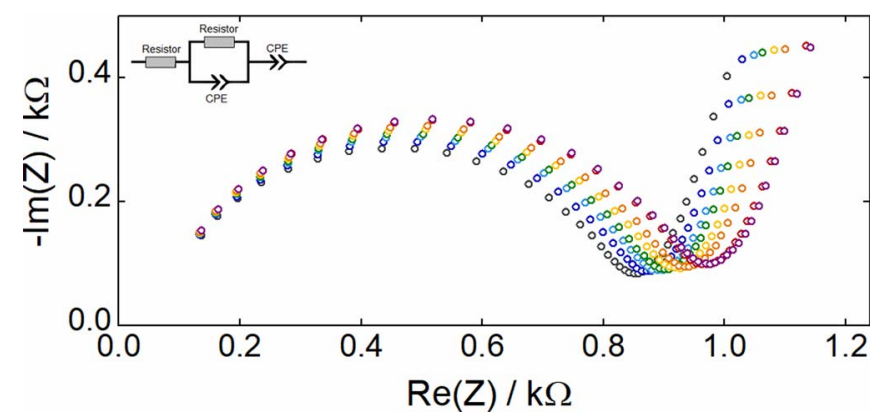

Figure 4. Nyquist diagram of the impedance of an SS $\mid \mathrm{PEO}_{15}$ LiTFSI $\mid$ LSPS $\mid \mathrm{PEO}_{15}$ LiTFSI $\mid \mathrm{SS}$ cell stored at $40^{\circ} \mathrm{C}$ after prior heating to $60^{\circ} \mathrm{C}(1 \mathrm{MHz}$ to $10 \mathrm{mHz}$ with $20 \mathrm{mV}$ amplitude). The arrow indicates the development over time, taken at 1-day intervals (blue: initial impedance, pink: after 7 days). The electric equivalent circuit used for fitting is shown in the top left.

yellow coloration of the PEO $_{15}$ LiTFSI membrane seen after cell disassembly (Figure S1).

Identification of the decomposition products.-In order to identify the decomposition products between LSPS and PEO ${ }_{15}$ LiTFSI, the cells were disassembled and the aged interfaces were investigated. XRD pattern of the aged samples were identical to those of pristine LSPS and PEO $_{15}$ LiTFSI, showing that the degradation products must be either amorphous or constitute very small fractions not detectable by XRD. XPS analysis, in contrast, revealed significant changes in the $S 2 p$ and $P 2 p$ spectra of the LSPS pellet surface which had been in contact with the $\mathrm{PEO}_{15}$ LiTFSI membrane in the cell at $60^{\circ} \mathrm{C}$ over appx. 7 days (Figure 5). We will first focus on the chemical environment of the sulfur atoms. An adequate fit of the $S 2 p$ detail spectra required modeling the signal with five doublets. The main signal at $168.9 \mathrm{eV}$ (S 2 $\mathrm{p}_{3 / 2}$; note that doublet binding energies are always referenced here to the lower binding energy peak of a doublet) marked by the gray areas in Figure 5 a represents the sulfur in $\left[\mathrm{SO}_{2}-\mathrm{CF}_{3}\right]$ units of LiTFSI, as shown by $\mathrm{Xu}$ et al. ${ }^{30}$ The signal at $161.2 \mathrm{eV}$ (marked in green), corresponding to the lowest oxidation state of sulfur, originates from the terminal sulfur in $\mathrm{PS}_{4}{ }^{3-}$ and $\mathrm{SnS}_{4}{ }^{4-}$ units of LSPS. Similar binding energies were already reported for LSPS as well as its derivate LGPS. ${ }^{36,43}$

The remaining three $S 2 p$ doublets could not be assigned to the pure compounds. Comparison to literature data indicates that the peak at $167.0 \mathrm{eV}$ (marked in red) derives from oxygen-bound sulfur, as reported for sulfites. ${ }^{43,46}$ The signal at $163.3 \mathrm{eV}$ (marked in yellow), which originates from sulfur in a lower oxidation state, most likely corresponds to the bridging sulfur atoms of polysulfide species: bridging sulfur atoms $\left(\mathrm{S}^{0}\right)$ are usually reported at $\mathrm{S} 2 \mathrm{p}_{3 / 2}$ binding energies of $163.1-163.9 \mathrm{eV}$, while terminal sulfur atoms $\left(\mathrm{S}^{-}\right)$usually appear in the range of $161.7-162.3 \mathrm{eV}^{46-49}$ It should be mentioned that the signal ratio as well as their exact binding energy depends on the polysulfide chain lengths, which however, cannot be quantified with certainty due to a strong overlap with the signals resulting from the bulk LSPS phase.

An adequate fit of the $\mathrm{P} 2 \mathrm{p}$ signal required two binding states to be considered. In accordance with Zhang et al., the main signal at $132.0 \mathrm{eV}\left(\mathrm{P} 2 \mathrm{p}_{3 / 2}\right)$ marked by the green area in Figure $5 \mathrm{~b}$ was assigned to phosphorus in a tetrahedral coordination with sulfur, namely to the $\mathrm{PS}_{4}{ }^{3-}$ units in LSPS. ${ }^{43} \mathrm{~A}$ second signal at $132.9 \mathrm{eV}$ (marked in blue) might originate from $\mathrm{P}-[\mathrm{S}]_{n}-\mathrm{P}$ type bonding configurations, e.g. represented by a $\mathrm{P}_{2} \mathrm{~S}_{7}{ }^{4-}$ unit, with the corresponding $\mathrm{S} 2 \mathrm{p}_{3 / 2}$ signal appearing at $162.9 \mathrm{eV}^{43,49} \mathrm{~A}$ similar binding energy was reported for $\mathrm{P}-\mathrm{S}-\mathrm{P}$ bonds in $\mathrm{P}_{2} \mathrm{~S}_{5}$ in a different study, also matching the $\mathrm{S} 2 \mathrm{p}_{3 / 2}$ doublets detected at $162.1 \mathrm{eV}$ and $163.5 \mathrm{eV} .{ }^{50}$ Note that due to smaller signal intensities in the $\mathrm{P} 2 \mathrm{p}$ region and a significant overlap of the doublets, quantification of the two components involves a high degree of uncertainty.
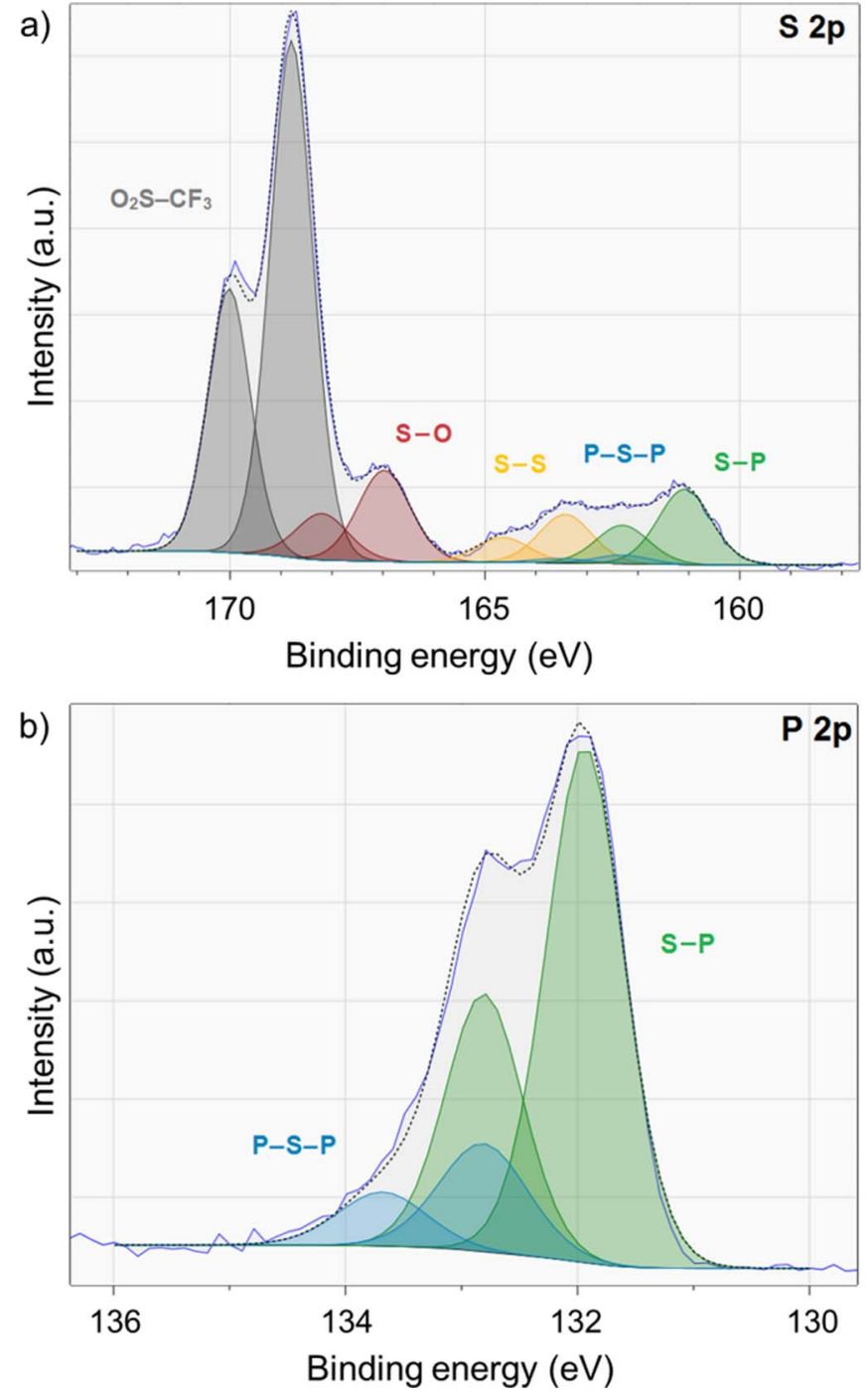

Figure 5. a) XPS S $2 p$ and b) XPS P $2 p$ spectra of the LSPS surface which was at the interface between LSPS and PEO $_{15}$ LiTFSI after aging in an SS | $\mathrm{PEO}_{15}$ LiTFSI | LSPS | $\mathrm{PEO}_{15}$ LiTFSI | SS cell at $60^{\circ} \mathrm{C}$ over appx. 7 days. Grey peaks are attributed to the $\left[\mathrm{SO}_{2}-\mathrm{CF}_{3}\right]$ unit in LiTFSI $(168.9 \mathrm{eV})$, red peaks to $\mathrm{S}-\mathrm{O}$ bonds in sulfite $(167.0 \mathrm{eV})$, yellow peaks to $\mathrm{S}-\mathrm{S}$ bonds in polysulfides $(163.3 \mathrm{eV})$, blue peaks to $\mathrm{P}-[\mathrm{S}]_{\mathrm{n}}-\mathrm{P}$ type bonds $(162.9 \mathrm{eV}$ for the $\mathrm{P} 2 \mathrm{p}$ and $132.9 \mathrm{eV}$ for the S $2 \mathrm{p}$ signals), and green peaks to $\mathrm{PS}_{4}{ }^{3-}$ or $\mathrm{SnS}_{4}{ }^{4-}$ bonds in LSPS (161.2 eV for the P $2 \mathrm{p}$ and $132.0 \mathrm{eV}$ for the $\mathrm{S} 2 \mathrm{p}$ signals). Note that doublet binding energies are always referenced here to the lower binding energy peak of a doublet.

Figure 6 depicts the FTIR spectra of an aged $\left(60^{\circ} \mathrm{C}\right.$ over appx. 7 days) PEO $_{15}$ LiTFSI | LSPS sample in comparison to the pristine materials. The shoulders emerging at 1030 and $1420 \mathrm{~cm}^{-1}$ can be attributed to $\mathrm{S}=\mathrm{O}$ vibrations (marked by red stars), as shown by Hesse et al. ${ }^{51} \mathrm{~S}-\mathrm{S}$ stretching vibrations in polysulfides (marked by the yellow star) usually yield weak bands around $500 \mathrm{~cm}^{-1} .{ }^{52}$ However, due to the strong overlap with S-P and S-Sn bands in LSPS, which appear around 400 and $570 \mathrm{~cm}^{-1}$, an unambiguous confirmation of polysulfides is not possible. Strong bands at 635,905 and $1615 \mathrm{~cm}^{-1}$ (green stars) match the values reported for $\mathrm{C}=\mathrm{C}-\mathrm{H}$ stretching vibrations. ${ }^{51,53}$ This indicates a reduction of the polymer accompanied by hydrogen or water release, which will be discussed later.

In order to confirm the development of polysulfides during aging of LSPS with PEO as suggested by XPS analysis (Figure 5a), UVVis spectroscopy based studies showed that the detected $\mathrm{S}_{\mathrm{n}}{ }^{2-}$ species thereby depends on the properties of the solvent. ${ }^{54-56}$ In solvents with 


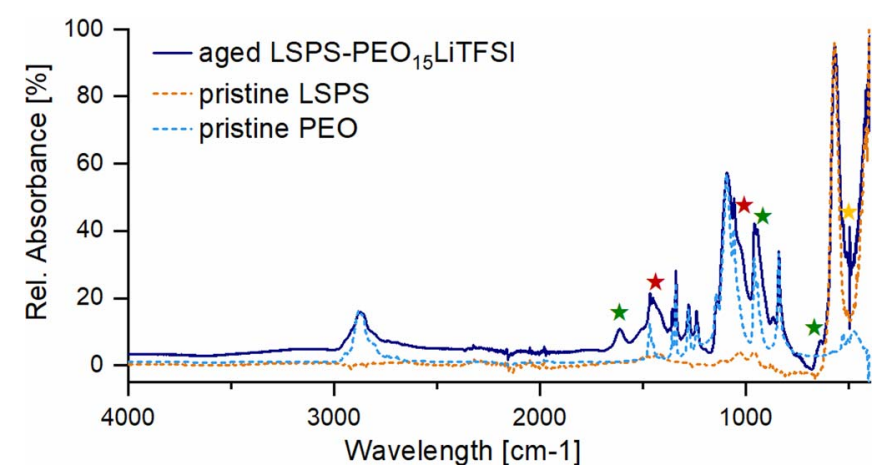

Figure 6. FTIR spectra of the aged LSPS $\mid \mathrm{PEO}_{15}$ LiTFSI interface (solid blue line) aged at $60^{\circ} \mathrm{C}$ over appx. 7 days compared to pristine LSPS (dashed orange line) and pristine PEO (dashed light blue line). Vibrations bands of S-S (yellow star), $\mathrm{S}=\mathrm{O}$ (red stars) and $\mathrm{C}=\mathrm{C}-\mathrm{H}$ bonds (green stars) are indicated for better visibility.

a high donor number, e.g. dimethyl sulfoxide or dimethylacetamide (DMA), multiple redox reactions involving $\mathrm{S}_{8}{ }^{2-}, \mathrm{S}_{6}{ }^{2-}, \mathrm{S}_{4}{ }^{2-}$ and $\mathrm{S}_{3}{ }^{-}$ species take place, with the strongly blue-colored $S_{3}{ }^{\cdot-}$ radical being the predominantly stabilized intermediate. In contrast, low donor number solvents such as 1,3-dioxolane or diglyme promote the formation of short-chain polysulfides, mostly the yellow-colored $\mathrm{S}_{4}{ }^{2-}$ anion. To determine whether polysulfides were produced during the aging of the $\mathrm{PEO}_{15}$ LiTFSI | LSPS interface at $60^{\circ} \mathrm{C}$ over 7 days, the aged $\mathrm{PEO}_{15}$ LiTFSI membranes were rinsed in DMA and diglyme, respectively. The DMA solution immediately turned blue while the yellow coloration of the polymer disappeared, indicating the presence of the blue $\mathrm{S}_{3}{ }^{-}$radical expected upon the solvation of polysulfides in DMA. With diglyme instead, the membrane had to be dissolved to obtain a yellow solution indicating short-chain polysulfides. Thus, the coloration of the solutions was a first indication for polysulfide species in the aged PEO $_{15}$ LiTFSI membrane, and several features characteristic of polysulfides were observed in the UV-Vis spectra of the solutions obtained with both solvents (Figure 7). As discussed above, the different donor properties of diglyme and DMA result in the stabilization of different polysulfide species. In diglyme, the UV-Vis features can be attributed to $\mathrm{S}_{2}{ }^{2-}(280 \mathrm{~nm})$ and $\mathrm{S}_{4}{ }^{2-}(345$ and $420 \mathrm{~nm})$, whereas $\mathrm{S}_{6}{ }^{2-}(338$ and $448 \mathrm{~nm})$ and $\mathrm{S}_{3}{ }^{-}(618 \mathrm{~nm})$ were detected in DMA. ${ }^{55,57}$ In summary, the expected speciation of polysulfides in the two solvents is an unambiguous proof of the formation of polysulfides in the PEO $_{15}$ LiTFSI membrane during the aging of the PEO $_{15}$ LiTFSI | LSPS interface at $60^{\circ} \mathrm{C}$. The existence of polysulfides in the aged PEO $_{15}$ LiTFSI membrane was also confirmed by Raman spectroscopy (not shown).

For further analysis, magic-angle-spinning (MAS) nuclear magnetic resonance (NMR) spectroscopy was performed on fresh LSPS and LSPS aged at $60^{\circ} \mathrm{C}$ over appx. 7 days in an SS $\mid \mathrm{PEO}_{15}$ LiTFSI LSPS | PEO 15 LiTFSI | SS cell. ${ }^{31} \mathrm{P}$ MAS NMR spectra of the fresh LSPS (Figure 8a, red line) revealed two strong peaks at $92.6 \mathrm{ppm}$ and $77.9 \mathrm{ppm}$, which represent isolated $\left[\mathrm{PS}_{4}\right]^{3-}$ units and can be assigned to the 2 a (occupied exclusively by $\mathrm{P}$ ) and $4 \mathrm{~d}$ sites (occupied by $\mathrm{Sn}$ and $\mathrm{P}$ in a ratio of 1:1) in the LSPS phase. ${ }^{35}$ Another peak is visible at $86.8 \mathrm{ppm}$, which is consistent with the presence of a small amount (15\%) of either $\mathrm{Li}_{7} \mathrm{PS}_{6}$ or $\mathrm{Li}_{3} \mathrm{PS}_{4}$. To clearly distinguish between the two, XRD analysis was performed. Rietveld refinement revealed $7.94 \% \mathrm{Li}_{7} \mathrm{PS}_{6}$ as the only side phase in pristine LSPS (Figure $\mathrm{S} 2$ ). This argyrodite, which can be described as a double salt of $\mathrm{PS}_{4}{ }^{3-}$ and $\mathrm{S}^{2-}$ anions, ${ }^{58}$ has recently been reported as a side phase of LSPS by Kaus et al. ${ }^{35}$ In addition, a small and rather broad ${ }^{31} \mathrm{P}$ MAS NMR peak is visible at $68 \mathrm{ppm}$ in Figure 8a, which hints at the presence of P-rich amorphous regions (1\%), and a small peak at $10 \mathrm{ppm}$ reveals the presence of a minor $\mathrm{Li}_{3} \mathrm{PO}_{4}$ contribution $(0.3 \%)$. The NMR spectrum of the aged LSPS (blue line) looks very similar to that of the fresh sample. The only clear difference is a broadening of the peak at
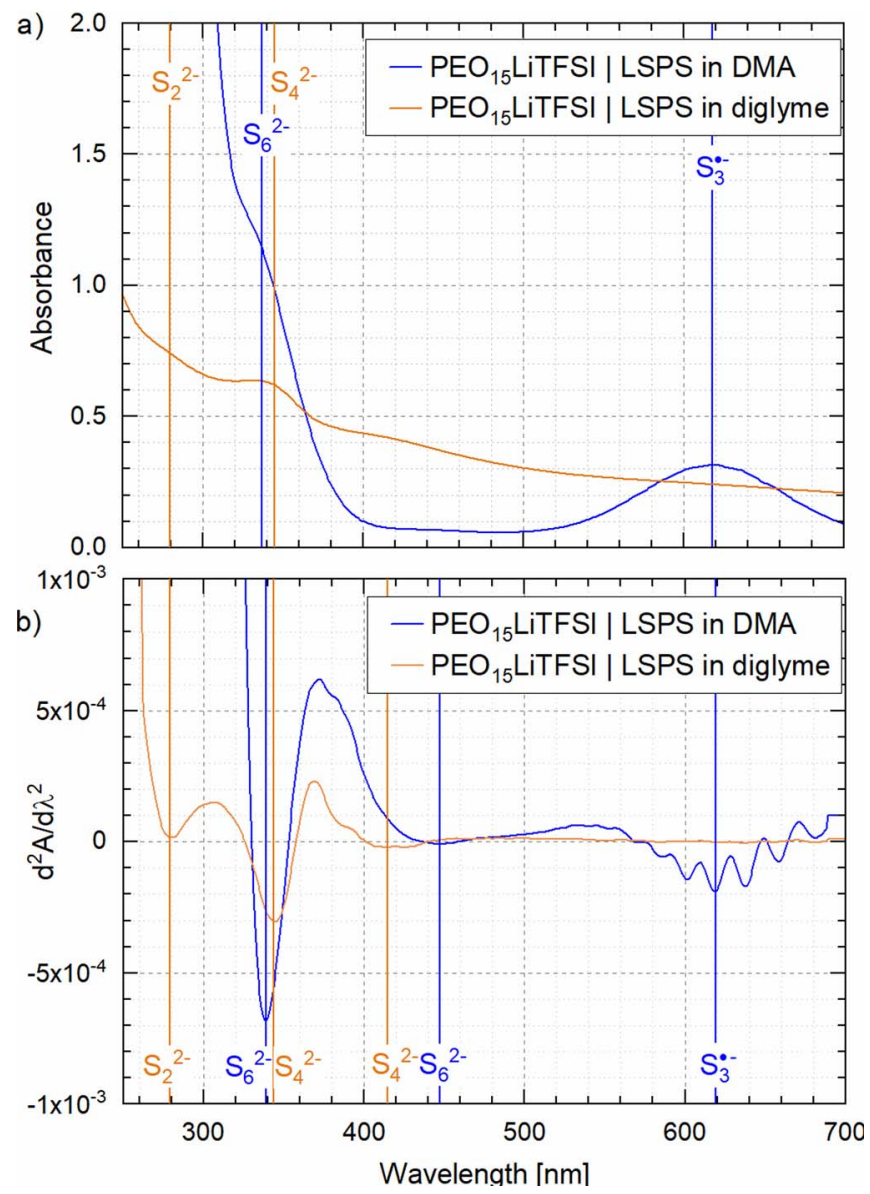

Figure 7. a) UV-Vis spectra of aged $\mathrm{PEO}_{15}$ LiTFSI membranes which were soaked in either DMA (blue) and diglyme (orange); membranes were aged at $60^{\circ} \mathrm{C}$ over appx. 7 days in an SS $\mid$ PEO $_{15}$ LiTFSI | LSPS | PEO 15 LiTFSI $\mid$ SS cell. b) $2^{\text {nd }}$ derivative of the absorbance to better detect the various spectral contributions: $\mathrm{S}_{2}{ }^{2-}$ at $280 \mathrm{~nm}, \mathrm{~S}_{4}{ }^{2-}$ at 345 and $420 \mathrm{~nm}, \mathrm{~S}_{6}{ }^{2-}$ at 338 and $448 \mathrm{~nm}, \mathrm{~S}_{3}{ }^{--}$at $618 \mathrm{~nm}$.

$86.8 \mathrm{ppm}$, which shows that the impurity phase undergoes an amorphization during aging. However, no conclusion with regard to the $\mathrm{P}-\mathrm{S}-\mathrm{P}$ type bonds suggested by XPS analysis (blue marked peaks in Figure 5b) can be drawn, as the expected signal would overlap with those of $\mathrm{Li}_{7} \mathrm{PS}_{6}$ or $\mathrm{Li}_{3} \mathrm{PS}_{4} .{ }^{59}$

The ${ }^{119}$ Sn MAS NMR spectra (Figure $8 b$ ) are again very similar for the fresh and the aged LSPS. A single peak at $87 \mathrm{ppm}$ can be assigned to the $\left[\mathrm{SnS}_{4}\right]^{--}$units in the LSPS phase. ${ }^{35}$ The asymmetry of this peak might hint at some Sn-P exchange between the $2 \mathrm{a}$ and $4 \mathrm{~d}$ sites. A slight broadening of this peak for the aged sample (blue line) might result from some increased structural disordering of the main phase. As in the ${ }^{31}$ P MAS NMR spectra, no additional phases can be evidenced.

Potential reasons for the decomposition of LSPS at the LSPS | PEO ${ }_{15}$ LiTFSI interface.-Polysulfides $\mathrm{S}_{\mathrm{n}}{ }^{2-}$, sulfite $\mathrm{SO}_{3}{ }^{2-}$ and $\mathrm{P}-[\mathrm{S}]_{\mathrm{n}}-\mathrm{P}$ type bridged $\mathrm{PS}_{4}{ }^{3-}$ units were identified as decomposition products in the previous section, without, however, discussion their possible origin. Within this part, conceivable reasons for the observed degradation products are reviewed. Before looking into contaminations and structural features of the two materials, the influence of temperature on decomposition was investigated. Therefore, calendar aging of SS | PEO $_{15}$ LiTFSI | LSPS | PEO $_{15}$ LiTFSI | SS cells and SS $\mid$ PEO $_{15}$ LiTFSI $\mid$ LSPS $\mid$ SS cells using LSPS powder was performed at 20,40 and $60^{\circ} \mathrm{C}$. Cell disassembly demonstrated the degradation enhancing effect of temperature, as samples stored at $60^{\circ} \mathrm{C}$ showed 
a) ${ }^{31} \mathrm{P}$ MAS NMR

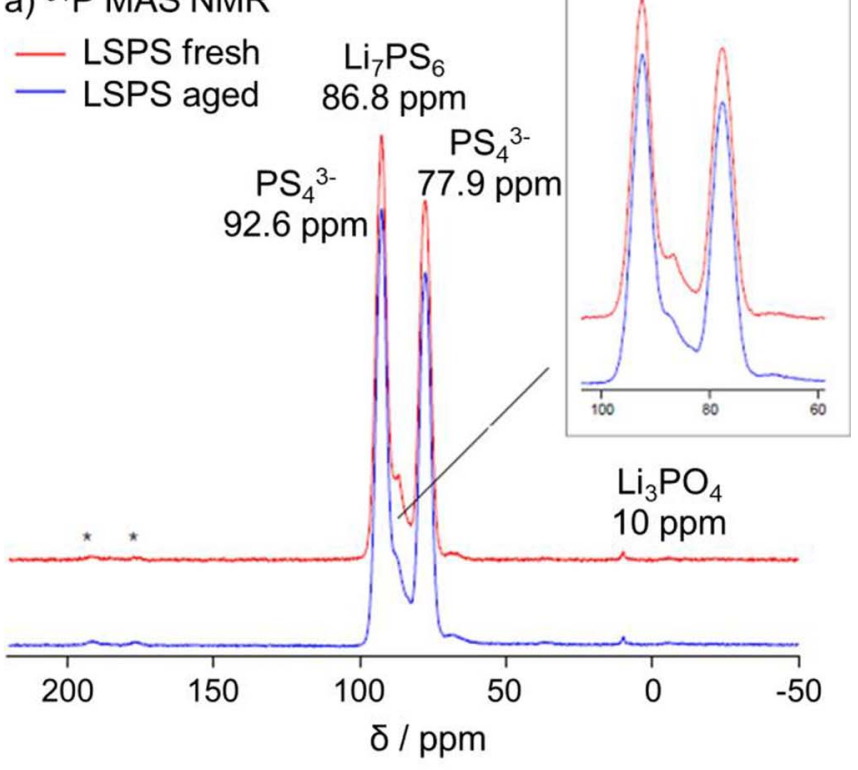

b) ${ }^{119} \mathrm{Sn}$ MAS NMR

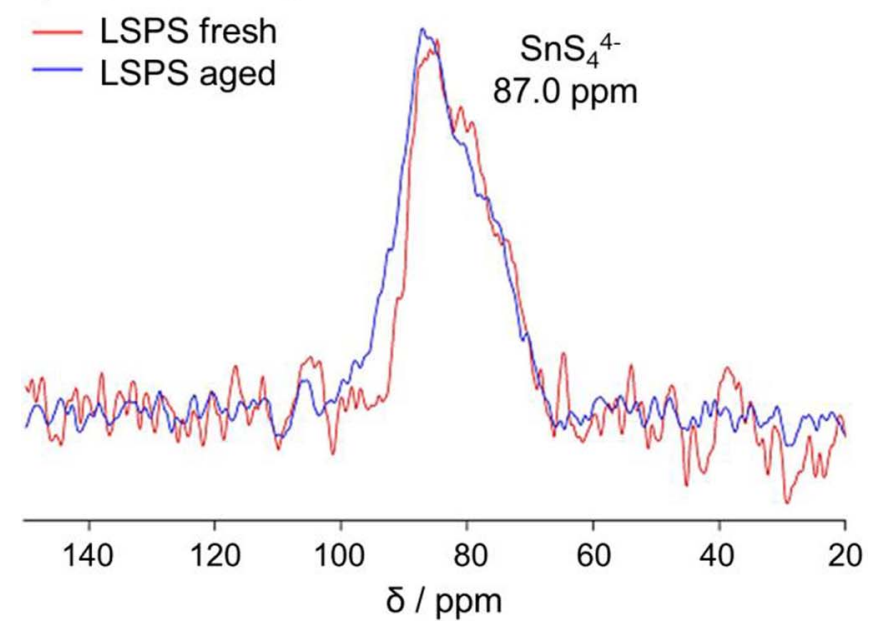

Figure 8. a) ${ }^{31} \mathrm{P}$ MAS NMR spectra of fresh (red) and aged (blue) LSPS. Peaks can be attributed to two isolated $\left[\mathrm{PS}_{4}\right]^{3-}$ units in LSPS, a $\mathrm{Li}_{7} \mathrm{PS}_{6}$ contamination, and a small fraction of $\mathrm{Li}_{3} \mathrm{PO}_{4}$. Comparison of the fresh and aged sample indicates a slight amorphization of the side phases in the aged sample. Spinning sidebands are marked with an asterisk. b) ${ }^{119}$ Sn MAS NMR spectra of fresh (red) and aged (blue) LSPS. The peak can be assigned to $\left[\mathrm{SnS}_{4}\right]^{4-}$ units in LSPS.

more intense coloration than those stored at $20^{\circ} \mathrm{C}$. This observation was supported by XPS analysis, which yielded a higher fraction of degradation products for the samples stored at $60^{\circ} \mathrm{C}$. Hence, the decomposition reaction seems to be kinetically controlled.

One conceivable origin of the observed degradation is a reaction of LSPS with traces of water in the system. PEO is known to trap water even throughout vacuum drying, and Karl-Fischer titration as well as FTIR spectroscopy were reported as suitable methods to explore this. ${ }^{30,60}$ However, both measurements, conducted with the pure materials and the hot-pressed $\mathrm{PEO}_{15}$ LiTFSI membranes, did not indicate any residual water. An alternative source of moisture could originate from leakage of the test cells. To fully exclude any possibility of moisture intrusion, several test cells were stored in argon-filled pouch bags sealed in the glove box. XPS analysis conducted after storage for one week at $60^{\circ} \mathrm{C}$ revealed the same degradation products for cells with and without additional sealing in pouch bags, so that leakage of ambient air into the cell could be ruled out as an origin of

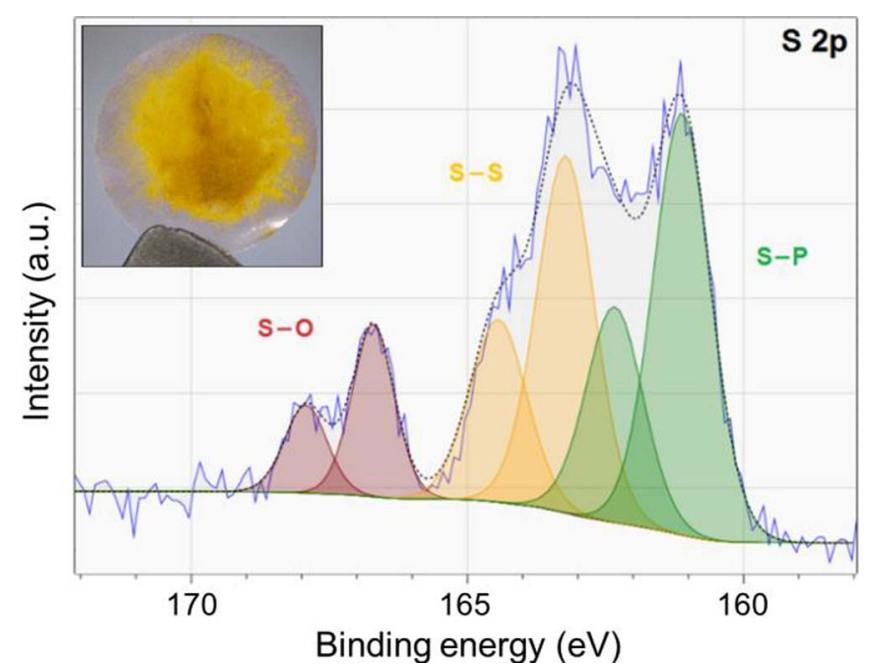

Figure 9. Image (top left) and XPS S $2 p$ spectra of a PEO membrane after aging in an SS | PEO | LSPS | SS cells using LSPS powder at $60^{\circ} \mathrm{C}$ over appx. 7 days. Red peaks are attributed to $\mathrm{S}-\mathrm{O}$ bonds in sulfite $(166.9 \mathrm{eV})$, yellow peaks to $\mathrm{S}-\mathrm{S}$ bonds in polysulfides $(163.4 \mathrm{eV})$ and green peaks to $\mathrm{PS}_{4}{ }^{3-}$ or $\mathrm{SnS}_{4}{ }^{4-}$ bonds in LSPS $(161.2 \mathrm{eV})$.

the decomposition. As a further test to exclude residual moisture or ambient air intrusion into the cell as the cause for the here observed LSPS, the reaction products of LSPS with water were examined. For this, a cell containing LSPS powder was purged with humidified argon that was saturated with water at $25^{\circ} \mathrm{C}$. Subsequent XPS and FTIR analysis revealed $\mathrm{Li}_{2} \mathrm{~S}, \mathrm{LiOH}$, elementary tin as well as reduced phosphorus species as the reaction products, next to only minor amounts of $\mathrm{SO}_{\mathrm{x}}$ compounds (Figure S3). Apparently, reaction with water results in a reduction of LSPS, whereas only oxidized species were found in

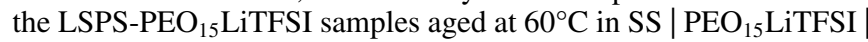
LSPS | PEO $_{15}$ LiTFSI | SS cells. This ultimately refutes the possibility that the reaction of LSPS with trace water impurities might be the origin of the observed decomposition.

In the next step, LiTFSI as the conductive salt was investigated. To exclude a possible reaction between LiTFSI and LSPS, PEO membranes without salt were prepared and stored in SS | PEO |LSPS | SS cells using LSPS powder. Cell disassembly after calendar aging for 7 days at $60^{\circ} \mathrm{C}$ revealed an intense yellow coloring, as observed for the

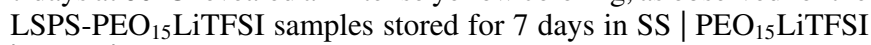
| LSPS | SS cells, and XPS as well as UV-Vis spectroscopy of the former confirmed the same degradation products. The XPS S $2 p$ spectrum is shown in Figure 9 together with an image of the aged salt-free PEO membrane, which is essentially identical with that shown in Fig-

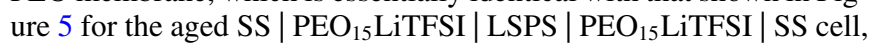
except for the absence of the LiTFSI features at $168.9 \mathrm{eV}$. These results do not only prove that the conductive salt is not required for the observed LSPS decomposition, but also demonstrate that all the sulfur-containing reaction products stem from the oxidative decomposition of LSPS. This was particularly surprising with regard to the sulfite species, which we considered to originate from LiTFSI before.

Since Blanga et al. did not report stability issues for their composite electrolyte based on PEO and LSPS, ${ }^{36}$ one could question whether contaminants in the pristine materials cause the decomposition. Beside the $\mathrm{Li}_{7} \mathrm{PS}_{6}$ phase identified by ${ }^{31} \mathrm{P}-\mathrm{NMR}$, XPS analysis of the raw materials indicated lithium hydroxide and carbonate as contaminants in LSPS (Figure S4). The assignment of the O 1s peak to LiOH was confirmed by comparative measurements of an LSPS-LiOH pellets (wt ratio 2:1), yielding an $\mathrm{O} 1 \mathrm{~s}$ signal at exactly the same binding energy. The pellets were moreover stored at $60^{\circ} \mathrm{C}$ for two weeks and analyzed via XPS. As no changes were observed in the spectra, LSPS and $\mathrm{LiOH}$ were proven to not react with each other (shown for the $\mathrm{S} 2 \mathrm{p}$ spectrum in Figure S5). The LiOH impurity though might react with PEO and thereby might lead to the observed degradation of LSPS. 
To probe this, an SS | LSPS-LiOH | PEO | SS cell was stored for appx. 7 days at $60^{\circ} \mathrm{C}$. Subsequent XPS analysis revealed a remarkably higher sulfite amount than in SS $\mid$ LSPS $\mid$ PEO | SS cells (Figure 9), and even traces of sulfate were detected (Figure S6). The same observation was made for SS | LSPS | PEO | SS cells aged for an extended time of appx. 6 weeks. Apparently, LiOH has a promoting effect on sulfite formation, indicating that it plays a role in the degradation mechanism.

In order to explain a reactivity of PEO with LSPS, we also took a closer look at the functional groups of the polymer. The here used PEO with an average molecular weight of $10^{6} \mathrm{~g} \cdot \mathrm{mol}^{-1}$ only features hydroxyl groups at the chain ends, from which a nominal hydroxyl mass fraction of $0.034 \mathrm{mg} \cdot \mathrm{g}^{-1}$ can be calculated. ${ }^{61}$ Despite this small value, a reactivity of these hydroxyl groups cannot be generally excluded. Their impact on the degradation reaction can be examined by replacing PEO by a similar polymer without hydroxyl groups. Polyethylene glycol dimethyl ether (PEGDME), which differs from PEO by having methoxy end groups, was selected to be tested against LSPS powder. XPS analysis after calendar aging of an SS | PEGDME | LSPS | SS cell for appx. 7 days at $60^{\circ} \mathrm{C}$ likewise yielded polysulfides, which was additionally verified by UV-Vis spectroscopy. In contrast to previous XPS experiments with aged LSPS-PEO samples (e.g. Figure 9), however, no $\mathrm{S}-\mathrm{O}$ species were detected in the $\mathrm{S} 2 \mathrm{p}$ spectrum (Figure S7). Apparently, removal of the hydroxyl functionality prevents sulfite formation, while the appearance of polysulfides is not affected by the presence/absence of hydroxyl functionalities. It seems that two different decomposition processes take place simultaneously at the LSPS | PEO interface. The tests with PEGDME revealed that sulfite formation is most likely caused by a reaction of LSPS with the hydroxyl groups of PEO and, with regard to the previous experiment, promoted by $\mathrm{LiOH}$ contaminations in pristine LSPS.

Discussion of a possible degradation mechanism.-Based on the above findings, the reactants involved in the decomposition reaction of LSPS and PEO are PEO itself, the $\mathrm{PS}_{4}{ }^{3-}$ units of LSPS and possibly $\mathrm{LiOH}$ impurities in LSPS. The resulting degradation products are polysulfides $\mathrm{S}_{\mathrm{n}}{ }^{2-}$, sulfite $\mathrm{SO}_{3}{ }^{2-}$ and $\mathrm{P}-[\mathrm{S}]_{\mathrm{n}}-\mathrm{P}$ type bridged $\mathrm{PS}_{4}{ }^{3-}$ units. As mentioned, comparative measurements indicated two degradation mechanisms. The hydroxyl groups in $\mathrm{PEO}$ and the $\mathrm{LiOH}$ contaminant in LSPS turned out to be involved in the oxidation of LSPS to sulfite, but polysulfides and $\mathrm{P}-[\mathrm{S}]_{\mathrm{n}}-\mathrm{P}$ units were also found in aged LSPS-PEGDME samples.

To the best of our knowledge, fundamental investigations of the chemical stability between organic polymers and sulfide-based inorganic SEs have not been conducted without applying electrochemistry so far. A literature research though revealed that the same degradation products were found in XPS studies of sulfide-based SEs in contact with cathode active materials in ASSBs after cycling. ${ }^{12,43,48-50}$ Auvergniot et al., for instance, reported the formation of polysulfides, $\mathrm{P}_{2} \mathrm{~S}_{5}$ and $\mathrm{LiCl}$ during oxidation of $\mathrm{Li}_{6} \mathrm{PS}_{5} \mathrm{Cl}$ in contact with $\mathrm{LiCoO}_{2} .{ }^{50}$ They moreover detected sulfite, which was attributed to the reaction of the argyrodite with traces of oxygen in the cell. Zhang et al. analyzed the interfacial properties of an LGPS/ $/ \mathrm{LiCoO}_{2} /$ carbon composite cathode, identifying $\mathrm{S}-\mathrm{O}, \mathrm{S}-\mathrm{S}, \mathrm{P}=\mathrm{S}$ and $\mathrm{P}-\mathrm{S}-\mathrm{P}$ type bonds formed during cycling. ${ }^{43}$ Similar observations were made by Koerver et al., who found $\mathrm{S}-\mathrm{S}$ and $\mathrm{P}-[\mathrm{S}]_{\mathrm{n}}-\mathrm{P}$ species in a composite cathode based on $\mathrm{LiNi}_{0.8} \mathrm{Co}_{0.1} \mathrm{Mn}_{0.1} \mathrm{O}_{2}$ (NMC) and $\beta-\mathrm{Li}_{3} \mathrm{PS}_{4}$ (LPS) after cycling. ${ }^{48,49}$

To better understand the connection between these oxidation reactions provoked by galvanostatic cycling and the oxidation processes herein, we took a deeper look into the underlying mechanisms. The formation of $\mathrm{P}-[\mathrm{S}]_{n}-\mathrm{P}$ bridges $(\mathrm{n} \geq 2)$ in a polymerization-like reaction of $\mathrm{PS}_{4}{ }^{3-}$ units was predicted in computational studies on the $\mathrm{LPS} / \mathrm{FePO}_{4}$ interface by Sumita et al. ${ }^{62,63}$ The reaction is accompanied by a decrease in Li-ion sites, and $\mathrm{Li}$-ion diffusion into the cathode is a driver for further oxidation. In a follow up experimental study, the behavior of LPS/carbon cathodes during Li deinsertion and insertion was examined ${ }^{64}$ Hakari et al. showed that the sulfide ions in LPS contribute to charge compensations. By XPS analysis it was demonstrated that the local bonding environment of phosphorus remained unchanged, but higher oxidation states were observed in $S 2 p$ spectra a)

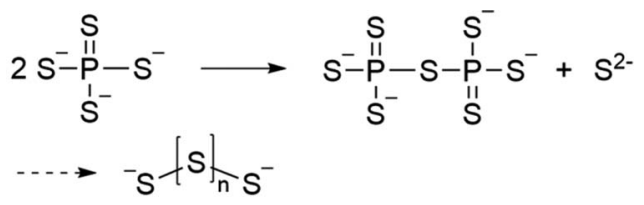

b)

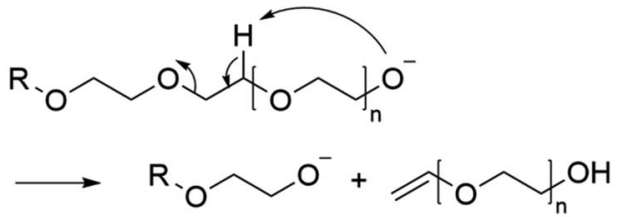

c)

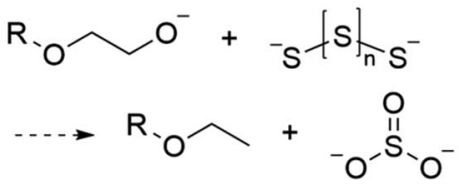

Scheme 1. Reaction scheme for a possible degradation mechanism of LSPS. (a) Reaction of $\mathrm{PS}_{4}{ }^{3-}$ units to $\mathrm{P}_{2} \mathrm{~S}_{7}{ }^{4-}$ units and polysulfides, analogous to what was proposed by Koerver et al. ${ }^{49}$ (b) Intramolecular fragmentation of deprotonated PEO, according to Hester et al. ${ }^{69}$ (c) Reaction of the alkoxides produced by reaction (b) with polysulfides produced by reaction (a) to sulfite and polymer fragments, inspired by Liang et al. ${ }^{47}$

of charged cathodes. The signal at $162.7 \mathrm{eV}$ was assigned to bridging sulfur atoms between $\mathrm{PS}_{4}{ }^{3-}$ units, which results in a formal sulfur oxidation state of -1 .

A similar reaction has recently been reported by Koerver et al., who also observed interconnection of $\mathrm{PS}_{4}{ }^{3-}$ units upon oxidation of an LPS/NMC/carbon composite. ${ }^{49}$ They presumed formation of cornerand edge-sharing species, namely $\mathrm{Li}_{4} \mathrm{P}_{2} \mathrm{~S}_{8}, \mathrm{Li}_{4} \mathrm{P}_{2} \mathrm{~S}_{7}$ or $\mathrm{Li}_{2} \mathrm{P}_{2} \mathrm{~S}_{6}$. In contrast to the polymerization proposed by Sumita et al., this reaction is not only accompanied by reduction of Li-ion sites, but also by sulfur release, resulting in a nominal loss of $\mathrm{Li}_{2} \mathrm{~S}$ (Scheme 1a). They stated that during the charging process sulfur might be accumulated in the cathode and Li-ions are transferred to the counter electrode. ${ }^{49,64} \mathrm{Ac}$ cording to various studies, the released sulfur most likely reacts with sulfide ions, which are e.g. present in the $\mathrm{Li}_{7} \mathrm{PS}_{6}$ side phase, to form polysulfides. ${ }^{43,48-50}$

Interestingly, Koerver et al. found the same oxidation products, albeit less intense, by XPS analysis of the LPS/carbon mixtures prior to electrochemical testing. ${ }^{49}$ This was not further commented, however regarding the results presented in our study, we suggest that cycling only accelerates the oxidation, but is not the actual trigger. Li extraction toward the counter electrode cannot be the driving force in this case, as the material was not exposed to a current or a potential. The same is true for the calendar aging tests shown here, suggesting that the LSPS decomposition mechanism involves a reaction with the PEO. Firstly, PEO is well-known to have a high Li-ion solvation ability, owing to its crown-ether-like structure that allows efficient complexation of Li-ions. ${ }^{3,40,65}$ Furthermore, several studies in the field of $\mathrm{Li} / \mathrm{S}$ battery research demonstrated that polysulfides can be dissolved in PEO, showing high mobility in Li/S cells with SPEs. ${ }^{66-68}$ It can therefore be assumed that removal of the LSPS decomposition products, i.e., of $\mathrm{Li}$-ions and polysulfides, into the polymer is a driving force for the oxidation of LSPS, following the principle of Le Chatelier.

The FTIR results moreover indicated that the polymer gets reduced, resulting in formation of $\mathrm{C}=\mathrm{C}$ double bonds. Hester et al. reported various fragmentation reactions for deprotonated PEO. ${ }^{69} \mathrm{LiOH}$ being present in pristine LSPS might act as a deprotonation agent. The formation of alkoxides has already been reported for the reaction of PEO with different alkali metal hydroxides by Xiao et al. ${ }^{70}$ In a subsequent intramolecular ether cleavage reaction, smaller fragments could emerge (Scheme 1b).$^{71}$ The fragmentation of PEO leads to a much higher amount of terminal oxygen than in the pristine material, which 
becomes relevant concerning sulfite formation. In search of a reaction mechanism, we found an interesting correlation with $\mathrm{Li} / \mathrm{S}$ batteries. Liang et al. showed that graphene oxide is reduced in contact with polysulfides. ${ }^{47}$ More precisely, they stated that $\mathrm{C}-\mathrm{OH}$ bonds get reduced to $\mathrm{C}-\mathrm{H}$ bonds during oxidation of polysulfides to thiosulfate. The formation of thiosulfate by oxidation of sulfur with metal hydroxide has also been reported earlier. ${ }^{72}$

In summary, a plausible degradation mechanism for LSPS could start with the polymerization of $\mathrm{PS}_{4}{ }^{3-}$ units. The released sulfur can react to polysulfides which are, likewise Li-ions, taken up by PEO. At the same time, the polymer could undergo an intramolecular fragmentation, which is accelerated by deprotonation of $\mathrm{PEO}$ with $\mathrm{LiOH}$. The resulting alkoxides might then react with polysulfides to form sulfite and polymer fragments (Scheme 1c). This mechanism would also explain the absence of sulfite species in LSPS-PEGDME samples, as the lack of a terminal hydroxyl group prohibits both the initial deprotonation and the subsequent intramolecular fragmentation to alkoxides.

\section{Conclusions}

In the present study, we analyzed the compatibility of the inorganic solid electrolyte LSPS with PEO-based polymer membranes.

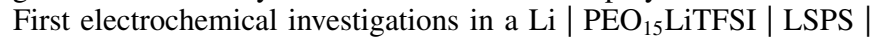
$\mathrm{PEO}_{15}$ LiTFSI $\mid$ Li cell demonstrated a continuous increase in the overall cell resistance, clearly indicating an ongoing degradation reaction

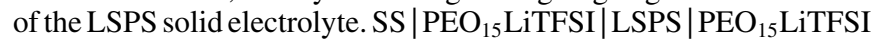
| SS cells where the lithium electrodes were replaced by stainless steel blocking electrodes showed an analogous impedance increase which could be ascribed to a growing impedance at the LSPS $\mid \mathrm{PEO}_{15} \mathrm{LiTFSI}$ interface caused by a reaction between these two materials. Subsequent XPS analysis, ${ }^{31} \mathrm{P}$ MAS NMR, and UV-Vis spectroscopic tests of the aged LSPS $\mid$ PEO $_{15}$ LiTFSI interface revealed polysulfides, $\mathrm{P}-[\mathrm{S}]_{\mathrm{n}}-\mathrm{P}$ type bridged $\mathrm{PS}_{4}{ }^{3-}$ units and sulfite as decomposition products. Additional experiments showed that artifacts due to reaction of LSPS with trace water impurities as well as the reaction of LSPS with the conductive salt LiTFSI could be ruled out as possible causes for the observed LSPS degradation. On the other hand, surface impurities on pristine LSPS as well as the hydroxyl end groups in PEO were found to affect the LSPS decomposition: while comparative tests showed that polysulfides are evolved independently of whether the end groups of the polymer were hydroxyl (in PEO) or methoxyl (in PEGDME) moieties sulfite is only formed in the presence of hydroxyl end groups (i.e. with PEO). Our data clearly prove that the LSPS | PEO interface is chemically instable, even in the absence of any electrochemistry. Based on a literature review, we proposed a plausible reaction mechanism for the purely chemical degradation of LSPS at the LSPS | PEO interface, considering not only the raw materials LSPS and PEO, but also contaminants such as lithium hydroxide on the LSPS surface.

We hereby want to highlight the importance of investigating interfaces in ASSBs both in terms of electrochemical and chemical properties. Regarding surface impurities and evaluating their role in potential unwanted side reactions is indispensable when analyzing electrochemical properties at the material level. Although surface impurities like lithium hydroxide or carbonate can be found in all types of battery materials, they are rarely taken into account when it comes to interpretation of the experimental data. This work shows that extensive post-mortem analysis is essential to get a complete picture of the interfacial reactions taking place in ASSBs.

\section{Acknowledgment}

The authors thank the BMW AG for the financial support of this work. Simon Qian, Qi He and Michele Piana from the Chair of Technical Electrochemistry (TEC) of the Technische Universität München are greatly acknowledged for their support with the UV-Vis measurements and the purging experiments with humidified argon, respectively.

\section{ORCID}

Nathalie Riphaus (D) https://orcid.org/0000-0001-5860-1106

Sylvio Indris (D) https://orcid.org/0000-0002-5100-113X

Stefan J. Sedlmaier (D https://orcid.org/0000-0002-5337-3076

\section{References}

1. J. Janek and W. G. Zeier, Nat. Energy, 1(9), 16141 (2016).

2. F. Mizuno, C. Yada, and H. Iba, in Lithium-Ion Batteries, p. 273, Elsevier B.V. 2014.

3. A. Varzi, R. Raccichini, S. Passerini, and B. Scrosati, J. Mater. Chem. A, 4(44), 17251 (2016).

4. D. Andre, H. Hain, P. Lamp, F. Maglia, and B. Stiaszny, J. Mater. Chem. A, 5(33), 17174 (2017).

5. W. Weppner, in Encyclopedia of Electrochemical Power Sources, p. 162, Elsevier B.V. 2009.

6. Y. Seino, T. Ota, K. Takada, A. Hayashi, and M. Tatsumisago, Energy Environ. Sci., 7(2), 627 (2014)

7. P. Bron, S. Johansson, K. Zick, Schmedt auf der Günne, Jörn. S. Dehnen, and B. Roling, J. Am. Chem. Soc., 135(42), 15694 (2013).

8. Y. Kato, S. Hori, T. Saito, K. Suzuki, M. Hirayama, A. Mitsui, M. Yonemura, H. Iba, and R. Kanno, Nat. Energy, 1(4), 16030 (2016).

9. N. Kamaya, K. Homma, Y. Yamakawa, M. Hirayama, R. Kanno, M. Yonemura, T. Kamiyama, Y. Kato, S. Hama, K. Kawamoto, and A. Mitsui, Nat. Mater, 10(9), 682 (2011).

10. C. Cao, Z.-B. Li, X.-L. Wang, X.-B. Zhao, and W.-Q. Han, Front. Energy Res., 2(Part 1), 947 (2014)

11. J. B. Goodenough and P. Singh, J. Electrochem. Soc., 162(14), A2387 (2015).

12. F. Han, T. Gao, Y. Zhu, K. J. Gaskell, and C. Wang, Adv. Mater, 27(23), 3473 (2015).

13. W. D. Richards, L. J. Miara, Y. Wang, J. C. Kim, and G. Ceder, Chem. Mater, 28(1), 266 (2016).

14. S. Wenzel, D. A. Weber, T. Leichtweiss, M. R. Busche, J. Sann, and J. Janek, Solid State Ionics, 286, 24 (2016)

15. S. Wenzel, S. Randau, T. Leichtweiss, D. A. Weber, J. Sann, W. G. Zeier, and J. Janek, Chem. Mater, 28(7), 2400 (2016).

16. Y. Zhu, X. He, and Y. Mo, ACS Appl. Mater. Interfaces, 7(42), 23685 (2015).

17. C. Yada, C. E. Lee, D. Laughman, L. Hannah, H. Iba, and B. E. Hayden, J. Electrochem. Soc., 162(4), A722 (2015).

18. K.-I. Chung, W.-S. Kim, and Y.-K. Choi, J. Electroanal. Chem., 566(2), 263 (2004).

19. M. Ogawa, R. Kanda, K. Yoshida, T. Uemura, and K. Harada, J. Power Sources, 205, 487 (2012).

20. K. Nagao, A. Hayashi, M. Deguchi, H. Tsukasaki, S. Mori, and M. Tatsumisago, J. Power Sources, 348, 1 (2017).

21. A. Kato, A. Hayashi, and M. Tatsumisago, J. Power Sources, 309, 27 (2016)

22. M. Nagao, A. Hayashi, and M. Tatsumisago, Electrochemistry, 80(10), 734 (2012).

23. B. Son, J. G. Kim, S. Mukherjee, N. Schuppert, A. Bates, O. Kwon, M. J. Choi, H. Y. Chung, and S. Park, J. Power Sources, 282, 299 (2015).

24. B. Zhu, Y. Jin, X. Hu, Q. Zheng, S. Zhang, Q. Wang, and J. Zhu, Adv. Mater, 29(2), (2017).

25. S. M. Choi, I. S. Kang, Y.-K. Sun, J.-H. Song, S.-M. Chung, and D.-W. Kim, J. Power Sources, 244, 363 (2013)

26. T. Zhang, N. Imanishi, S. Hasegawa, A. Hirano, J. Xie, Y. Takeda, O. Yamamoto, and N. Sammes, J. Electrochem. Soc., 155(12), A965 (2008)

27. T. Shodai, J. Electrochem. Soc., 141(10), 2611 (1994).

28. H. H. Sumathipala, J. Hassoun, S. Panero, and B. Scrosati, J. Appl. Electrochem., 38(1), 39 (2007)

29. Y.-C. Jung, M.-S. Park, D.-H. Kim, M. Ue, A. Eftekhari, and D.-W. Kim, Sci. Rep., 7(1), $17482(2017)$

30. C. Xu, B. Sun, T. Gustafsson, K. Edström, D. Brandell, and M. Hahlin, J. Mater. Chem. A, 2(20), 7256 (2014).

31. S.-D. Lee, K.-N. Jung, H. Kim, H.-S. Shin, S.-W. Song, M.-S. Park, and J.-W. Lee, ChemSusChem, 10(10), 2175 (2017).

32. W. Zhou, S. Wang, Y. Li, S. Xin, A. Manthiram, and J. B. Goodenough, J. Am. Ceram. Soc., 138(30), 9385 (2016).

33. W. Zhou, Y. Li, S. Xin, and J. B. Goodenough, ACS Cent. Sci., 3(1), 52 (2017).

34. W. E. Tenhaeff, X. Yu, K. Hong, K. A. Perry, and N. J. Dudney, J. Electrochem. Soc., 158(10), A1143 (2011).

35. M. Kaus, H. Stöffler, M. Yavuz, T. Zinkevich, M. Knapp, H. Ehrenberg, and S. Indris, J. Phys. Chem. C, 121(42), 23370 (2017).

36. R. Blanga, M. Goor, L. Burstein, Y. Rosenberg, A. Gladkich, D. Logvinuk, I. Shechtman, and D. Golodnitsky, J. Solid State Electrochem., 20(12), 3393 (2016).

37. T. Abe, M. Ohtsuka, F. Sagane, Y. Iriyama, and Z. Ogumi, J. Electrochem. Soc., 151(11), A1950 (2004).

38. G. B. Appetecchi, S. Scaccia, and S. Passerini, J. Electrochem. Soc., 147(12), 4448 (2000).

39. E. Quartarone and P. Mustarelli, Chem. Soc. Rev., 40(5), 2525 (2011)

40. Z. Xue, D. He, and X. Xie, J. Mater. Chem. A, 3(38), 19218 (2015).

41. F. M. Gray, Solid Polymer Electrolytes: Fundamentals and Technological Applications: Solid Polymer Electrolytes: Fundamentals and Technological Applications, Wiley-VCH, Weinheim 1991.

42. P. Bron, S. Dehnen, and B. Roling, J. Power Sources, 329, 530 (2016). 
43. W. Zhang, T. Leichtweiss, S. P. Culver, R. Koerver, D. Das, D. A. Weber, W. G. Zeier, and J. Janek, ACS Appl. Mater. Interfaces, 2017.

44. P. Schichtel, M. Geiß, T. Leichtweiss, J. Sann, D. A. Weber, and J. Janek, J. Power Sources, 360, 593 (2017).

45. I. Ismail, A. Noda, A. Nishimoto, and M. Watanabe, Electrochim. Acta, 46(10-11), 1595 (2001).

46. M. Fantauzzi, B. Elsener, D. Atzei, A. Rigoldi, and A. Rossi, RSC Adv, 5(93), 75953 (2015).

47. X. Liang, C. Hart, Q. Pang, A. Garsuch, T. Weiss, and L. F. Nazar, Nat. Comm., 6, 5682 (2015).

48. R. Koerver, I. Aygün, T. Leichtweiss, C. Dietrich, W. Zhang, J. O. Binder, P. Hartmann, W. G. Zeier, and J. Janek, Chem. Mater, 29(13), 5574 (2017).

49. R. Koerver, F. Walther, I. Aygün, J. Sann, C. Dietrich, W. Zeier, and J. Janek, J. Mater Chem. A, (5), 22750 (2017).

50. J. Auvergniot, A. Cassel, D. Foix, V. Viallet, V. Seznec, and R. Dedryvère, Solid State Ionics, 300, 78 (2017).

51. M. Hesse, H. Meier, and B. Zeeh, Spektroskopische Methoden in der organischen Chemie, Stuttgart etc., G. Thieme 2005.

52. C. N. R. Rao, R. Venkataraghavan, and T. R. Kasturi, Can. J. Chem., 42(1), 36 (1964)

53. B. C. Smith, Infrared Spectral Interpretation: A Systematic Approach, Taylor \& Francis 1998.

54. Y.-C. Lu, Q. He, and H. A. Gasteiger, J. Phys. Chem. C, 118(11), 5733 (2014).

55. Q. Zou and Y.-C. Lu, J. Phys. Chem. Lett., 7(8), 1518 (2016).

56. Q. He, Y. Gorlin, M. U. M. Patel, H. A. Gasteiger, and Y.-C. Lu, J. Electrochem. Soc., 165(16), A4027 (2018).
57. N. S. A. Manan, L. Aldous, Y. Alias, P. Murray, L. J. Yellowlees, M. C. Lagunas, and C. Hardacre, J. Phys. Chem. B, 115(47), 13873 (2011).

58. H. Eckert, Z. Zhang, and J. H. Kennedy, Chem. Mater., 2(3), 273 (1990).

59. C. Dietrich, D. A. Weber, S. J. Sedlmaier, S. Indris, S. P. Culver, D. Walter, J. Janek, and W. G. Zeier, J. Mater. Chem. A, 5(34), 18111 (2017).

60. S. J. Wen, T. J. Richardson, D. I. Ghantous, K. A. Striebel, P. N. Ross, and E. J. Cairns, J. Electroanal. Chem., 408(1-2), 113 (1996).

61. H. F. Mark, Encyclopedia of Polymer Science and Engineering, New York, Wiley 1985.

62. M. Sumita, Y. Tanaka, and T. Ohno, J. Phys. Chem. C, 121(18), 9698 (2017).

63. M. Sumita, Y. Tanaka, M. Ikeda, and T. Ohno, J. Phys. Chem. C, 120(25), 13332 (2016).

64. T. Hakari, M. Deguchi, K. Mitsuhara, T. Ohta, K. Saito, Y. Orikasa, Y. Uchimoto, Y. Kowada, A. Hayashi, and M. Tatsumisago, Chem. Mater. 29(11), 4768 (2017).

65. M. Armand, Adv. Mater., 2(6-7), 278 (1990).

66. F. Lee, M.-C. Tsai, M.-H. Lin, Y. L. Ni'mah, S. Hy, C.-Y. Kuo, J.-H. Cheng, J. Rick, W.-N. Su, and B.-J. Hwang, J. Mater. Chem. A, 5(14), 6708 (2017)

67. H. Zhong, C. Wang, Z. Xu, F. Ding, and X. Liu, Sci. Rep., 6, 25484 (2016).

68. J. Chen, W. A. Henderson, H. Pan, B. R. Perdue, R. Cao, J. Z. Hu, C. Wan, K. S. Han, K. T. Mueller, J.-G. Zhang, Y. Shao, and J. Liu, Nano Lett., 17(5), 3061 (2017).

69. T. H. Hester, D. E. Castillo, and D. J. Goebbert, Rapid Communications in Mass Spectrometry, 27(14), 1643 (2013).

70. Y. Xiao, J. Jiang, and H. Huang, Sci. Rep., 4, 6305 (2014).

71. C. Elschenbroich, Organometallics, s.l., Wiley-VCH 2016.

72. H. V. Tartar and C. Z. Draves, J. Am. Chem. Soc., 46(3), 574 (1924). 